\title{
RESEARCH ON DISPERSION IN INDENTER AND REFERENCE BLOCK FOR ROCKWELL HARDNESS TEST
}

\author{
Takeshi Sawa ${ }^{1}$ \\ ${ }^{1}$ Mitutoyo Corporation, 1-20-1 Sakado, Takatsu-ku, Kawasaki-shi, Kanagawa-ken, 213-8533, Japan \\ takeshi_sawa@mitutoyo.co.jp
}

\begin{abstract}
:
In this report, the Rockwell indenters and hardness reference blocks obtained from different three manufacturers were evaluated. And these results with the tolerances for the indirect verification prescribed in ISO 6508-2 and ASTM E18 were compared, it has been suggested that the tolerances prescribed in ASTM E18 might be too strict in view of actual circumstances.
\end{abstract}

Keywords: Rockwell indenter, hardness reference block, ISO/IEC 17025, ISO standards, ASTM standards

\section{INTRODUCTION}

The importance of ensuring the traceability in measurement has been increased in these years, and accordingly, the spread of systems certifying tests and calibrations in conformity with ISO/IEC 17025[1] that can publicly give assurance has been promoted in a worldwide manner. In addition, the Mutual Recognition Agreement (MRA) that mutually certifies the conformity assessment results of own country as equivalent to another country is implemented among many accredited systems, and the accredited certificates are valid in any countries. It can be said that this system is extremely beneficial for globalization of manufacturing and industry. The hardness test is no exception, and the number of cases where the calibration of hardness reference blocks, indenters and hardness testing machines is requested to conform to ISO/IEC 17025 is increasing. It can be said that the supply source of indenters and hardness reference blocks that are used for calibration of hardness testing machines does not matter if the testing and calibration are performed in conformity with accredited systems system. However, a hardness value is industrial quantity and has no physical reference, therefore, the traceability system and uncertainty evaluation method for measurement values and calibration values are not completely standardized in the global aspect under present circumstances. Such present circumstances may become a problem for calibration of hardness testing machines. We know that even differences in hardness values among national metrology institute level are a problem for calibration of actual hardness testing machines [2]. In this report, evaluating the dispersion of Rockwell indenters and hardness reference blocks obtained from different three manufacturers have been conducted for the purpose of investigating the realistic circumstances. Then, based on these results, the uncertainty of calibration in indirect verification of the hardness testing machine was estimated, and the consistency with the tolerance value prescribed in the standard was investigated.

\section{EXPERIMENT}

Three pieces of Rockwell diamond conical indenters, tungsten carbide ball indenters with $1.5875 \mathrm{~mm}$ in diameter and six types of hardness reference blocks from three manufacturers are obtained. The scales and hardness levels of the six hardness reference blocks were $30 \mathrm{HRC}, 60 \mathrm{HRC}$, $90 \mathrm{HR} 15 \mathrm{~N}, 30 \mathrm{HRBW}, 90 \mathrm{HRBW}$ and $35 \mathrm{HR}$ 15TW. Three manufacturers are hereinafter referred to as Manufacturer A, Manufacturer B, and Manufacturer C. Manufacturer A is a famous indenter and reference block manufacturer in Europe. Manufacturer B and Manufacturer C are US manufacturers and a lot of their products are widespread in the United States. An accredited certificate is issued for all of these indenters and reference blocks to prove that calibration of them conforming to ISO/IEC 17025 has been conducted. SHT-31, a Rockwell hardness standard testing machine manufactured by Mitutoyo Corporation, was used for evaluation. The specifications and accuracy of each part of the testing machine is conformed to ISO 6508-3: calibration of the hardness reference block [3]. Moreover, the testing conditions such as time of loading the testing force and duration time were set according to this standard. 


\subsection{Results of evaluating indenters of each manufacturer}

Testing on the same reference block with the use of obtained indenters and our indenter were conducted. Our indenter, i.e. Mitutoyo indenter is conformable to ISO 6508-3, and is equivalent to an indenter classified in Class A prescribed in ASTM E18[4]. The differences between the hardness values of the targeted indenters to be evaluated and the hardness value of our indenter were evaluated. Figure 1 shows the differences of hardness values in each scale. The medians were regarded as the average of the differences of hardness values in each scale. The value $P_{\mathrm{I}}$ shows a $95 \%$ confidence interval of dispersion calculated by multiplying the experimental standard deviation of the differences of hardness values in each scale by a coverage factor. Here, the coverage factor was determined to be 2.31 on the basis of the Student's t-distribution in consideration that the degree of freedom of data in each scale is 8 .

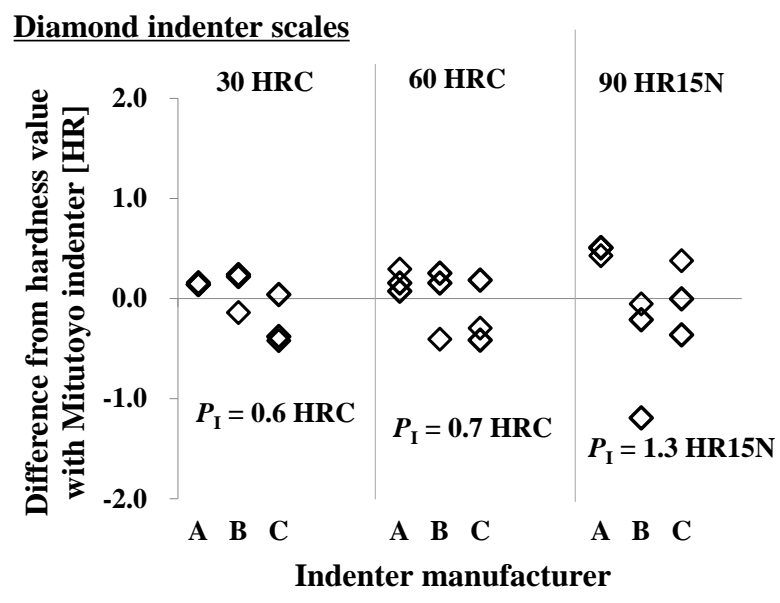

WC ball indenter scales

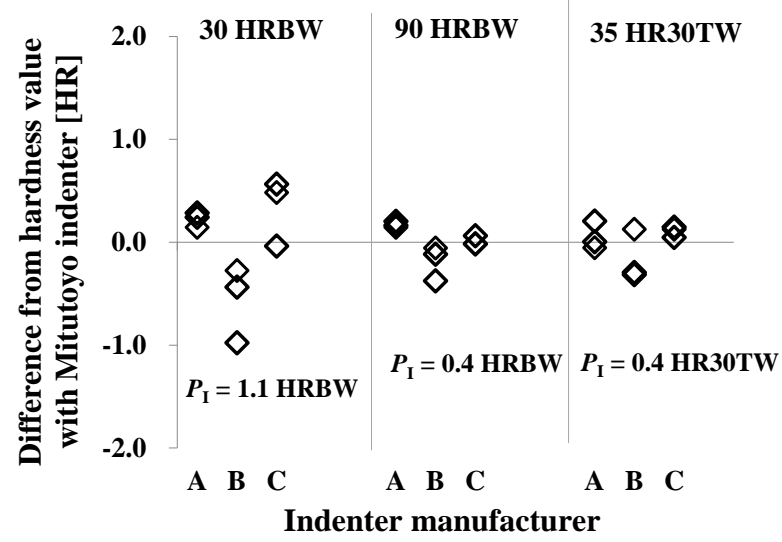

Figure 1: Difference from hardness value with Mitutoyo indenter

\subsection{Results of evaluating obtained reference blocks of each manufacturer}

Testing on the obtained reference blocks with the use Mitutoyo indenter were conducted, and the measured hardness values were compared with the calibration values of the targeted hardness reference blocks to be evaluated. Figure 2 shows the differences from the calibration values of the reference blocks in each scale. The medians were regarded as the average of the differences of hardness values in each scale. The value $P_{\mathrm{B}}$ shows a 95\% confidence interval of dispersion calculated by multiplying the experimental standard deviation of the differences of hardness values in each scale by a coverage factor. Here, the coverage factor was determined to be 2.31 on the basis of the Student's $\mathrm{t}$-distribution in consideration that the degree of freedom of data in each scale is 8 .

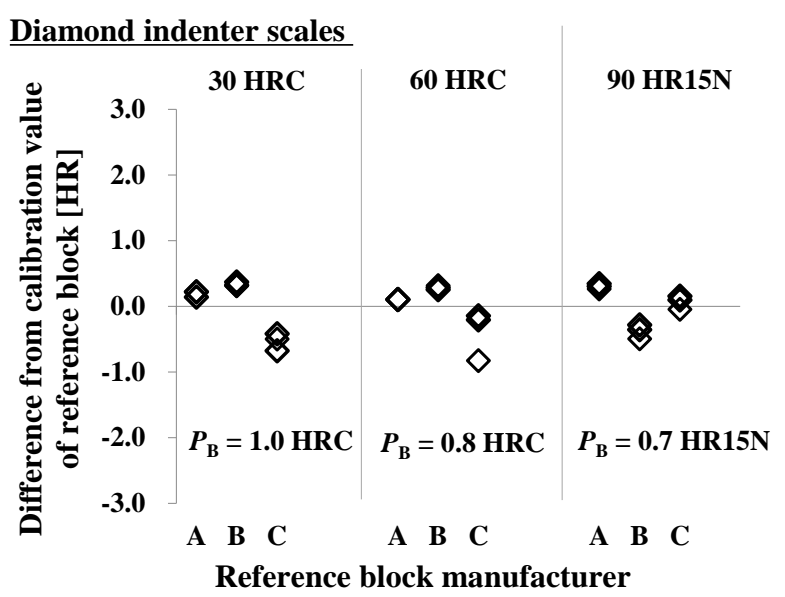

WC ball indenter scales

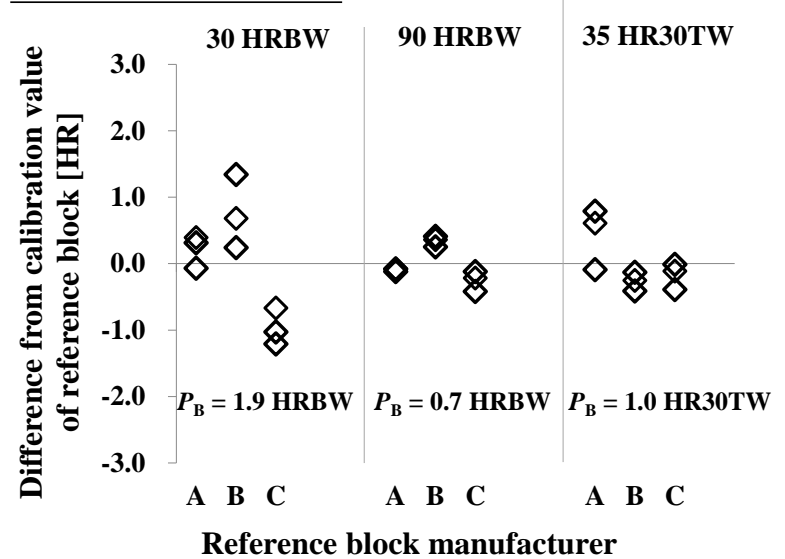

Figure 2: Differences from the calibration values of the reference blocks

\section{DISCUSSION}

\subsection{Regarding results of evaluating indenters}

Table 1 shows the $P_{\mathrm{I}}$ value in Fig. 1 and the tolerance of indenter prescribed in ISO 6508-2[5] and ASTM E18. For diamond indenter, the difference from the reference indenter is prescribed in standard as tolerance. There are some $P_{\mathrm{I}}$ values that are larger than the tolerance. This fact suggests that indenters whose tolerance exceeds the standards may be on the market. 
For tungsten carbide ball indenter, the difference from the calibration value of reference block is in standard as tolerance. Except for $30 \mathrm{HRBW}$, the $P_{\mathrm{I}}$ value is sufficiently smaller than the tolerance of standard. However, this result is a difference from the value measured with the same testing machine and test conditions, and the uncertainty of the calibration value of reference block is considered to be larger than measured value. That is, the fact that the $P_{\mathrm{I}}$ value is smaller is expected result. Nevertheless, for $30 \mathrm{HRBW}$, the $P_{\mathrm{I}}$ value exceeds the tolerance of ASTM standard. In addition, there is a bias of indenters among manufacturers. That is, for $30 \mathrm{HRBW}$, it is suggested that the use of indenter from another manufacturer may exceed the tolerance of ASTM standard.

Table 1: Evaluation results of indenter and tolerance of standard

\begin{tabular}{|c|c|c|c|}
\hline Scale & $\begin{array}{c}\text { Tolerance } \\
\text { (ISO 6508-2) }\end{array}$ & $\begin{array}{c}\text { Tolerance } \\
\text { (ASTM E18) }\end{array}$ & $\begin{array}{c}\text { Experimental result } \\
\left(P_{\mathrm{I}} \text { value }\right)\end{array}$ \\
\hline $30 \mathrm{HRC}$ & $0.8 \mathrm{HRC}$ & $0.8 \mathrm{HRC}$ & $0.6 \mathrm{HRC}$ \\
\hline $60 \mathrm{HRC}$ & $0.8 \mathrm{HRC}$ & $0.4 \mathrm{HRC}$ & $0.7 \mathrm{HRC}$ \\
\hline $90 \mathrm{HR} 15 \mathrm{~N}$ & $0.8 \mathrm{HR} 15 \mathrm{~N}$ & $0.5 \mathrm{HR} 15 \mathrm{~N}$ & $1.3 \mathrm{HR} 15 \mathrm{~N}$ \\
\hline $30 \mathrm{HRBW}$ & 4.0 HRBW & $0.8 \mathrm{HRBW}$ & 1.1 HRBW \\
\hline $90 \mathrm{HRBW}$ & 2.0 HRBW & $0.8 \mathrm{HRBW}$ & 0.4 HRBW \\
\hline 35 HR30TW & 3.0 HR30TW & 0.8 HR30TW & 0.4 HR30TW \\
\hline
\end{tabular}

\subsection{Estimation of uncertainty for indirect verification using results of evaluating reference block.}

The disperse i.e. uncertainty of hardness values generated in the indirect verification of the testing machine was estimated. As factors for the uncertainty, we hypothesized the influences of the depth measuring device, difference of the indenter with respect to the reference indenter, the calibration value and uniformity of the hardness reference block, and machine hysteresis. It thought that the testing force, indentation time, and duration time of testing force can be ignored because these factors have little influence. The standard uncertainty for each factor was estimated based on the description in Table 2. If a tolerance is different between the ISO standards and ASTM standards, stricter tolerance was used for estimation. Table 3 shows the uncertainty budget for each scale.
Table 2: Hypothesized uncertainty factors

\begin{tabular}{ll}
\hline $\begin{array}{l}\text { Uncertainty } \\
\text { factors }\end{array}$ & $\begin{array}{l}\text { Hypothesized variation of hardness } \\
\text { values }\end{array}$ \\
\hline $\begin{array}{l}\text { Depth measuring } \\
\text { device }\end{array}$ & $\begin{array}{l}\text { Tolerances in verification of depth } \\
\text { measuring device prescribed in ISO } \\
6508-2 \text { and ASTM E18 }\end{array}$ \\
$\begin{array}{l}\text { Diamond } \\
\text { indenter }\end{array}$ & $\begin{array}{l}\text { Tolerance of difference in hardness value } \\
\text { from reference indenter at testing with } \\
\text { the identical reference block prescribed } \\
\text { in ASTM E18 }\end{array}$ \\
Ball indenter & $\begin{array}{l}\text { Tolerance of difference in calibration } \\
\text { value from reference block at testing } \\
\text { reference block prescribed in ASTM E18 }\end{array}$ \\
$\begin{array}{l}\text { Tolerance of difference between the } \\
\text { maximum and minimum values in 5- } \\
\text { reference block }\end{array}$ & $\begin{array}{l}\text { point measurement prescribed in } \\
\text { standard for reference block, ISO 6508-3 } \\
\text { or ASTM E18 }\end{array}$ \\
$\begin{array}{l}P_{\mathrm{B} \text { values in Fig. 2 are hypothesized as }} \\
\text { expanded uncertainty. }\end{array}$ \\
$\begin{array}{l}\text { Calibration value } \\
\text { of reference } \\
\text { block }\end{array}$ & $\begin{array}{l}\text { Although the tolerance is } \pm 1.0 \text { HR in ISO } \\
\text { Machine } \\
\text { deformation }\end{array}$ \\
$\begin{array}{l}\text { to be } \pm 0.3 \text { HR in view of actual } \\
\text { circumstances. }\end{array}$ \\
\hline
\end{tabular}

\subsection{Regarding consistency with the tolerance of the standard}

Table 4 shows the tolerances in indirect verification prescribed in ISO 6508-2, ASTM E18 and estimated expanded uncertainty. When the expanded uncertainty of the hardness value in indirect verification is compared with the tolerance of the standard, it is considered that the uncertainty is within the tolerance range of the ISO standards in all the evaluated scales. With regard to the ASTM standards, on the other hand, the uncertainty may not be within the tolerance range except for 30 HRBW and 35 HR30TW through the indirect verification even with the use of indenters and reference blocks that are conformable with the standards. The tolerance of $30 \mathrm{HRBW}$ in the ASTM standards was revised from $\pm 1.5 \mathrm{HRBW}$ to \pm 2.5 HRBW in 2019, and it is thought that review in light of present circumstances is conducted. However, even for $30 \mathrm{HRBW}$ and $35 \mathrm{HR} 30 \mathrm{TW}$, the margin for the tolerance is small, and the tolerance may not be appropriate.

In this report, the estimated expanded uncertainty of the hardness value in indirect verification is the result of extracting only main uncertainty factors, and is obtained by using the smaller tolerance between two types of standards. In addition, experimental estimation of indenters and hardness reference blocks was conducted only about three manufacturers. Thus, the actual uncertainty may be even larger. Regardless of the above, when the dispersion is compared with the tolerance of the ASTM standards, the dispersion is equivalent to or 
exceeds the tolerance. Especially regarding $60 \mathrm{HRC}$, the difference between the tolerance $\pm 0.5 \mathrm{HRC}$ of indirect verification prescribed in the ASTM standards and the dispersion of the estimated hardness values is large. This fact suggests that the tolerance of ASTM standards is not realistic.

Table 3: Uncertainty budget for each scale $30 \mathrm{HRC}$

\begin{tabular}{|c|c|c|c|c|}
\hline Factor & Range $( \pm)$ & Distribution & Divisor & Standard uncertainty \\
\hline Depth measuring & $0.5 \mathrm{HRC}$ & Rectanglar & $\sqrt{3}$ & $0.289 \mathrm{HRC}$ \\
\hline Indenter & $0.4 \mathrm{HRC}$ & Rectanglar & $\sqrt{3}$ & $0.231 \mathrm{HRC}$ \\
\hline Uniformity of block & 0.35 HRC & Rectanglar & $\sqrt{3} \times \sqrt{5}$ & $0.090 \mathrm{HRC}$ \\
\hline Uncertainty of block & $1.0 \mathrm{HRC}$ & Normal & 2 & $0.500 \mathrm{HRC}$ \\
\hline Machine hysteresis & $0.3 \mathrm{HRC}$ & Rectanglar & $\sqrt{3}$ & $0.173 \mathrm{HRC}$ \\
\hline \multicolumn{4}{|c|}{ Combined standard uncertainty } & 0.652 HRC \\
\hline \multicolumn{4}{|c|}{ Expanded uncertainty $(k=2)$} & $1.3 \mathrm{HRC}$ \\
\hline
\end{tabular}

$60 \mathrm{HRC}$

\begin{tabular}{lcccc}
\hline \multicolumn{1}{c}{ Factor } & Range $( \pm)$ & Distribution & Divisor & Standard uncertainty \\
\hline Depth measuring & $0.5 \mathrm{HRC}$ & Rectanglar & $\sqrt{3}$ & $0.289 \mathrm{HRC}$ \\
Indenter & $0.4 \mathrm{HRC}$ & Rectanglar & $\sqrt{ } 3$ & $0.231 \mathrm{HRC}$ \\
Uniformity of block & $0.2 \mathrm{HRC}$ & Rectanglar & $\sqrt{3} \times \sqrt{5}$ & $0.052 \mathrm{HRC}$ \\
Uncertainty of block & $0.8 \mathrm{HRC}$ & Normal & 2 & $0.400 \mathrm{HRC}$ \\
Machine hysteresis & $0.3 \mathrm{HRC}$ & Rectanglar & $\sqrt{3}$ & $0.173 \mathrm{HRC}$ \\
\hline \multicolumn{2}{c}{ Combined standard uncertainty } & $0.574 \mathrm{HRC}$ \\
\hline \multicolumn{3}{c}{ Expanded uncertainty $(k=2)$} & & $1.1 \mathrm{HRC}$ \\
\hline
\end{tabular}

$90 \mathrm{HR} 15 \mathrm{~N}$

\begin{tabular}{lcccc}
\hline \multicolumn{1}{c}{ Factor } & Range $( \pm)$ & Distribution & Divisor & Standard uncertainty \\
\hline Depth measuring & $0.5 \mathrm{HR} 15 \mathrm{~N}$ & Rectanglar & $\sqrt{3}$ & 0.289 HR15N \\
Indenter & $0.5 \mathrm{HR} 15 \mathrm{~N}$ & Rectanglar & $\sqrt{3}$ & 0.289 HR15N \\
Uniformity of block & $0.25 \mathrm{HR} 15 \mathrm{~N}$ & Rectanglar & $\sqrt{3} \times \sqrt{5}$ & 0.065 HR15N \\
Uncertainty of block & $0.7 \mathrm{HR} 15 \mathrm{~N}$ Normal & 2 & $0.350 \mathrm{HR} 15 \mathrm{~N}$ \\
Machine hysteresis & $0.3 \mathrm{HR} 15 \mathrm{~N}$ Rectanglar & $\sqrt{3}$ & $0.173 \mathrm{HR} 15 \mathrm{~N}$ \\
\hline \multicolumn{2}{c}{ Combined standard uncertainty } & & $0.569 \mathrm{HR} 15 \mathrm{~N}$ \\
\hline \multicolumn{2}{c}{ Expanded uncertainty $(k=2)$} & & $1.1 \mathrm{HR} 15 \mathrm{~N}$ \\
\hline
\end{tabular}

\section{HRBW}

\begin{tabular}{lcccc}
\hline \multicolumn{1}{c}{ Factor } & Range $( \pm)$ & Distribution & Divisor & Standard uncertainty \\
\hline Depth measuring & 0.5 HRBW & Rectanglar & $\sqrt{3}$ & 0.289 HRBW \\
Indenter & 0.8 HRBW & Rectanglar & $\sqrt{3}$ & 0.462 HRBW \\
Uniformity of block & 0.5 HRBW Rectanglar & $\sqrt{3} \times \sqrt{5}$ & 0.129 HRBW \\
Uncertainty of block & 1.9 HRBW Normal & 2 & 0.950 HRBW \\
Machine hysteresis & 0.3 HRBW Rectanglar & $\sqrt{3}$ & 0.173 HRBW \\
\hline \multicolumn{2}{c}{ Combined standard uncertainty } & & 1.116 HRBW \\
\hline \multicolumn{2}{c}{ Expanded uncertainty $(k=2)$} & & 2.2 HRBW \\
\hline
\end{tabular}

$90 \mathrm{HRBW}$

\begin{tabular}{lcccc}
\hline \multicolumn{1}{c}{ Factor } & Range $( \pm)$ & Distribution & Divisor & Standard uncertainty \\
\hline Depth measuring & 0.5 HRBW & Rectanglar & $\sqrt{3}$ & 0.289 HRBW \\
Indenter & 0.8 HRBW & Rectanglar & $\sqrt{3}$ & 0.462 HRBW \\
Uniformity of block & 0.35 HRBW & Rectanglar & $\sqrt{3} \times \sqrt{5}$ & 0.090 HRBW \\
Uncertainty of block & 0.7 HRBW Normal & 2 & 0.350 HRBW \\
Machine hysteresis & 0.3 HRBW Rectanglar & $\sqrt{3}$ & 0.173 HRBW \\
\hline \multicolumn{2}{c}{ Combined standard uncertainty } & & 0.676 HRBW \\
\hline \multicolumn{3}{c}{ Expanded uncertainty $(k=2)$} & & 1.4 HRBW
\end{tabular}

\begin{tabular}{|c|c|c|c|c|}
\hline Factor & Range $( \pm)$ & Distribution & Divisor & Standard uncertainty \\
\hline Depth measuring & $0.5 \mathrm{HR} 30 \mathrm{~T}$ & Rectanglar & $\sqrt{3}$ & 0.289 HR30TW \\
\hline Indenter & 0.8 HR30T & Rectanglar & $\sqrt{3}$ & 0.462 HR30TW \\
\hline Uniformity of block & 0.5 HR30T & Rectanglar & $\sqrt{3} \times \sqrt{5}$ & 0.129 HR30TW \\
\hline Uncertainty of block & 1.0 HRBW & Normal & 2 & $0.500 \mathrm{HR} 30 \mathrm{TW}$ \\
\hline Machine hysteresis & $0.3 \mathrm{HR} 30 \mathrm{~T}$ & Rectanglar & $\sqrt{3}$ & 0.173 HR30TW \\
\hline \multicolumn{4}{|c|}{ Combined standard uncertainty } & 0.770 HR30TW \\
\hline \multicolumn{4}{|c|}{ Expanded uncertainty $(k=2)$} & 1.5 HR30TW \\
\hline
\end{tabular}

Table 4: Tolerance of standards and estimated extended uncertainty in indirect verification

\begin{tabular}{cccc}
\hline Scale & $\begin{array}{c}\text { Tolerance } \\
\text { (ISO 6508-2) }\end{array}$ & $\begin{array}{c}\text { Tolerance } \\
\text { (ASTM E18) }\end{array}$ & $\begin{array}{c}\text { Analysis } \\
\text { (Expanded uncertainty) }\end{array}$ \\
\hline $30 \mathrm{HRC}$ & $1.5 \mathrm{HRC}$ & $1.0 \mathrm{HRC}$ & $1.3 \mathrm{HRC}$ \\
$60 \mathrm{HRC}$ & $1.5 \mathrm{HRC}$ & $0.5 \mathrm{HRC}$ & $1.1 \mathrm{HRC}$ \\
$90 \mathrm{HR} 15 \mathrm{~N}$ & $2.0 \mathrm{HR} 15 \mathrm{~N}$ & $0.7 \mathrm{HR} 15 \mathrm{~N}$ & $1.1 \mathrm{HR} 15 \mathrm{~N}$ \\
$30 \mathrm{HRBW}$ & $4.0 \mathrm{HRBW}$ & $2.5 \mathrm{HRBW}$ & $2.2 \mathrm{HRBW}$ \\
& & & $1.4 \mathrm{HRBW}$ \\
90 HRBW & $2.0 \mathrm{HRBW}$ & $1.0 \mathrm{HRBW}$ & \\
& & & $1.5 \mathrm{HR} 30 \mathrm{TW}$ \\
\hline
\end{tabular}

\section{SUMMARY}

The following items including verification and evaluation were conducted and described in this report.

- Evaluation of the dispersion of indenters and hardness reference blocks which are in the market.

- Comparison of evaluation result and tolerances for indenter.

- Estimation of uncertainty of hardness value in indirect verification of the testing machine based on the evaluation result of the reference block.

- Verification of validity of the tolerance in the indirect verification prescribed in the ISO standards and ASTM standards.

By conducting the items above, and the following were found.

- For diamond indenter, there is a possibility that the indenters exceed the tolerance of standard are in market.

- For tungsten carbide ball indenters, there is a possibility that the difference may exceed the tolerance of standard for $30 \mathrm{HRBW}$ if the indenter manufacturer changes.

- It was suggested that the estimated dispersion of the hardness values generated in indirect verification fell under the tolerance range of the ISO standards.

- It was suggested that the estimated dispersion of the hardness values generated in indirect verification exceed the tolerance range of the ASTM standards, and in particular, the tolerance of ASTM standard for 60 HRC may be too strict.

\section{CONCLUSION}

A hardness value is not a physical quantity, but an industrial quantity obtained by a prescribed testing method. The fact is that testing machines and testing conditions vary within the prescribed tolerance range and relatively large dispersion of hardness values is observed even in a national standard level. If the fact that this is a destructive 
test in which absolute reference does not exist is considered, it can be said that such dispersion is generated as a matter of course. On the other hand, under such circumstances, accredited systems and traceability are utilized. This type of issue may be a big problem that cannot be solved by company alone for manufacturers of hardness testing machines in each country. We hope that verification of consistency with public standards becomes emphasis for the sake of the industrial world.

\section{REFERENCES}

[1] ISO/IEC 17025:2017 General requirements for the competence of testing and calibration laboratories.

[2] T. Sawa, "Current state of Rockwell hardness in the world", Proceedings of IMEKO World Congress, Belfast, UK, 2018.

[3] ISO 6508-3:2015 Metallic materials Rockwell hardness test: Calibration of reference blocks.

[4] ASTM E18-20 Standard Test Methods for Rockwell Hardness of Metallic Materials.

[5] ISO 6508-2:2015 Metallic materials Rockwell hardness test: Verification and calibration of testing machines. 